\title{
A Normalized Hysteretic Energy Spectrum for Energy-Based Seismic Design
}

\author{
Cuiling $\mathrm{Ma}^{1}{ }^{1}$, Changbing $\mathrm{Chen}^{1}$,Xiaotang $\mathrm{Lv}^{1}$, Jian Bian ${ }^{2}$,Yuan Feng ${ }^{2}$ and Hui Liu ${ }^{2}$ \\ ${ }^{1}$ College of Urban Construction and Transportation, Hefei University, Hefei 230601, China \\ ${ }^{2}$ College of Advanced Manufacturing Engineering, Hefei University, Hefei 230601, China
}

\begin{abstract}
To disclose the impacts of hysteretic energy (HE) demand on energy-based seismic design, this paper introduces the dimensionless parameter $\beta_{E H}$ to express the cumulative HE indirectly and establishes the $\beta_{E H}$ spectrum for energy-based seismic design. After analyzing numerous seismic responses of a single degree-of-freedom (SDOF) system, the author set up a simplified $\beta_{E H}$ spectral formula based on the genetic algorithm. Then, 750 ground motion records were selected according to Chinese site classification, and used to examine the effects of soil type and damping ratio on the $\beta_{E H}$ spectra. The results show that the soil type, site group and damping ratio have significant effects on the $\beta_{E H}$ spectra; the ductility ratio has an impact on the spectral value but not the spectral shape.
\end{abstract}

\section{Introduction}

Proposed by Housner [1], the energy-based seismic design involves more ground motion features (e.g. acceleration amplitude, spectral features and seismic duration) than force- and displacement-based seismic designs. The more rational seismic design approach in terms of energy is gaining extensive attention(Akiyama [2][3]; Uang and Bertero [4]; Goel [5]; Leelataviwat et al. [6];Choi and Kim [7];Sahoo and Chao [8]; Kharmale and Ghosh [9]; Habibi et al.[10];Heidari and Gharehbaghi [11]).

The hysteretic energy (HE) demand is the key to the energy-based seismic design, owing to its relevance to the cumulative structural damage induced by seismic activity. Considering its simplicity, convenience and applicability, scholars at home and abroad have proposed various forms of HE spectra. For instance, Mckevitt et al. [12] analyzed the HE of multi-story buildings under seismic excitation, revealing that most $\mathrm{HE}$ is dissipated from the bottom floor of the structure under the uniform distribution of stiffness and strength along the structural height. Khashaee P. [13] established an HE spectrum in light of the field effects and ground motion features, such as severity, duration and frequency. Through linear and nonlinear dynamic analysis, López-Almansa et al. [14] derived the HE spectrum of equivalent velocity ratio from the record of strong earthquakes in Turkey, while considering the impacts of soil type and earthquake magnitude. On 89 pairs of bidirectional seismic motion records, Wang et al. [15, 16] established the mean normalized input energy spectra and HE spectra, and created a normalized HE spectrum of constant ductility ratios to estimate the story $\mathrm{HE}$ demand, where the normalized $\mathrm{HE}$ is defined as the ratio of the HE to the square of the peak ground acceleration (PGA). Sun et al. [17] defined the ratio of the equivalent velocity of HE to the peak ground velocity (PGV) as a dimensionless parameter $\beta_{\mathrm{Eh}}$ for indirect expression of the $\mathrm{HE}$, developed the $\beta_{\mathrm{Eh}}$ spectra against the regression results (e.g. seismic impact, soil type, damping ratio and ductility) on various seismic responses of the single degree-of-freedom (SDOF) system, and set up the relationship between the PGV and the PGA. Dogru et al. [18] assessed the energy parameters against the total energy input and HE for special steel concentrically braced frames (CBFs) with different heights, conducted nonlinear dynamic time history analysis on the HE variation along the frame height, and eventually derived the seismic energy demand spectrum and HE distributions of the CBFs.

In general, none of the existing HE spectra refers to Chinese site classifications. The Chinese codes divide the building sites into five classes, and further split each class into three groups, according to the predominant period of ground motion. This paper selected 750 ground motion records by Chinese site classification, and derived the simplified $\beta_{\mathrm{EH}}$ spectra of cumulative HE demand using the energy-balance equation of SDOF system. In addition, the author examined the effects of soil type, structural damping ratio and ductility ratio over the HE spectra, and presented the mathematical expression of simplified $\beta_{\mathrm{EH}}$ spectrum.

\section{ENERGY - BALANCE EQUATION AND SPECTRAL PARAMETERS 2.1 Energy-balance equation}

\footnotetext{
* Corresponding author:hanjingling19@sina.com
} 
Bruneau and Wang [19] advised to calculate the seismic input energy by the relative energy equation.Under unidirectional horizontal ground motion,the relative motion equation of an elastic-plastic SDOF system can be written as:

$$
m \ddot{x}+c \dot{x}+f_{s}=-m \ddot{x}_{g}
$$

where $m$ is the mass; $c$ is the viscous damping coefficient; $f_{\mathrm{s}}$ is the restoring force; $x, \dot{x}$ and $\ddot{x}$ are the relative displacement, velocity and acceleration of the mass with respect to ground, respectively; $\ddot{x}_{g}$ is the ground acceleration.

The energy equation can be derived from equation (1) through integration over the entire seismic duration:

$$
\int_{0}^{t} m \ddot{x} \dot{x} d t+\int_{0}^{t} c \dot{x} \dot{x} d t+\int_{0}^{t} f_{s} \dot{x} d t=-\int_{0}^{t} m \ddot{x_{g}} \dot{x} d t
$$

where $\mathrm{t}$ is time.

Equation (2) can be rewritten as:

$E_{K \mathrm{r}}+E_{D}+E_{E}+E_{H}=E_{I \mathrm{r}}$

where $E_{k r}$ is the kinetic energy; $E_{D}$ is the energy dissipated by viscous damping; $E_{E}$ is the elastic strain energy stored in the SDOF system; $E_{H}$ is the HE dissipated from inelastic behaviors; $E_{I r}$ is the total input energy induced by the earthquake.

In far-field earthquakes, structural failure is mainly caused by the cumulative damage from the cyclic effect and gradual accumulation of oscillation-induced seismic energy. Thus, the cumulative HE can reasonably describe the far-field seismic damage. Then, the $E_{H}$ can be expressed as an equivalent velocity $V_{\mathrm{EH}}[20]$ :

$$
V_{E H}=\sqrt{\frac{2 E_{H}}{m}}
$$

where $m$ is the mass.Finally, the dimensionless parameter $\beta_{E H}$ can be defined as the ratio of the equivalent velocity of $\mathrm{HE}$ to the PGV [17]:

$$
\beta_{E H}=\frac{V_{E H}}{P G V}
$$

\subsection{Spectral parameters}

The selected SDOF system satisfies the forcedisplacement relationship of the bilinear elastic-plastic model. The post-yielding stiffness ratio (PYSR) was set to 0.05 and 0.00 , the damping ratio $\zeta$ to $0.01 \sim 0.20$, and the ductility ratio $\mu$ to $1 \sim 10$.

\section{Ground Motion Records}

A total of 750 ground motion records were extracted from the PEER Ground Motion Database according to the geological conditions of various seismic stations [21] and the Code for Seismic Design of Buildings [22]. The number and percentage of ground motion records in each site type are respectively presented in Table 1 and Table 2.

In Chinese codes,according to the equivalent shear wave velocity of the soil layer and the thickness of the site cover, the building sites can be divided into soil type I,II,III,IV.It should be mentioned that Lv [23],by analyzing a number of geological prospecting data of U.S. station sites, concluded that China's soil type I corresponds to the site class A and B and a part of site class C of U.S., China's soil type II is between site class C and D of U.S., China's soil type III is between site class D and E of U.S., and China's soil type IV is

\begin{tabular}{|c|c|c|c|c|c|c|}
\hline \multirow[t]{2}{*}{ Soil type } & \multicolumn{6}{|c|}{ Moment magnitude } \\
\hline & $\begin{array}{c}4< \\
M \\
\leq 5\end{array}$ & $\begin{array}{c}5< \\
M \\
\leq 6\end{array}$ & $\begin{array}{c}6< \\
M \\
\leq 7\end{array}$ & $\begin{array}{c}7<\mathrm{M} \\
\leq 8\end{array}$ & Total & $\begin{array}{c}\text { Propo } \\
\text { rtion }\end{array}$ \\
\hline Soil type $I$ & 0 & 4 & 100 & 16 & 120 & $\begin{array}{c}16.0 \\
\%\end{array}$ \\
\hline Soil type $I I$ & 0 & 64 & 387 & 78 & 529 & $\begin{array}{c}70.5 \\
\%\end{array}$ \\
\hline $\begin{array}{c}\text { Soil type } \\
I I I\end{array}$ & 2 & 0 & 73 & 8 & 83 & $\begin{array}{c}11.1 \\
\%\end{array}$ \\
\hline $\begin{array}{c}\text { Soil type } \\
I V\end{array}$ & 0 & 4 & 8 & 6 & 18 & $2.4 \%$ \\
\hline Total & 2 & 72 & 568 & 108 & 750 & \\
\hline Percentage & $0.3 \%$ & $9.6 \%$ & $\begin{array}{c}75.7 \\
\%\end{array}$ & $\begin{array}{c}14.4 \\
\%\end{array}$ & & \\
\hline
\end{tabular}
identical with U.S. site class E.

Table 1. Statistics of ground motion records based on moment magnitude according to soil type of Chinese code.

\begin{tabular}{|c|c|c|c|c|c|c|c|}
\hline \multirow[b]{2}{*}{ Soil type } & \multicolumn{7}{|c|}{ Epicenter distance $(\mathrm{km})$} \\
\hline & $\begin{array}{c}30< \\
\mathrm{R} \\
\leq 50\end{array}$ & $\begin{aligned} & 50 \\
< & \mathrm{R} \\
\leq & 80\end{aligned}$ & $\begin{array}{c}80<\mathrm{R} \\
\leq 120\end{array}$ & $\begin{array}{c}120< \\
\mathrm{R} \leq 20 \\
0\end{array}$ & $\begin{array}{c}200< \\
\mathrm{R}\end{array}$ & Total & $\begin{array}{l}\text { Propo } \\
\text {-rtion }\end{array}$ \\
\hline $\begin{array}{c}\text { Soil type } \\
I\end{array}$ & 26 & 38 & 14 & 24 & 18 & 120 & $\begin{array}{c}16.0 \\
\%\end{array}$ \\
\hline $\begin{array}{c}\text { Soil type } \\
I I\end{array}$ & 120 & 128 & 89 & 106 & 86 & 529 & $\begin{array}{c}70.5 \\
\%\end{array}$ \\
\hline $\begin{array}{c}\text { Soil type } \\
I I I\end{array}$ & 8 & 21 & 12 & 20 & 22 & 83 & $\begin{array}{c}11.1 \\
\%\end{array}$ \\
\hline $\begin{array}{c}\text { Soil type } \\
I V\end{array}$ & 2 & 6 & 2 & 6 & 2 & 18 & $2.4 \%$ \\
\hline Total & 156 & 193 & 117 & 156 & 128 & 750 & \\
\hline $\begin{array}{l}\text { Propo- } \\
\text { rtion }\end{array}$ & $\begin{array}{c}20.8 \\
\%\end{array}$ & $\begin{array}{c}25.7 \\
\%\end{array}$ & $15.6 \%$ & $20.8 \%$ & $17.1 \%$ & & \\
\hline
\end{tabular}

Table 2. Statistics of ground motion records based on epicenter distance according to soil type of Chinese code

In the above Chinese code, the impacts of seismic environment on the acceleration response spectrum is 
measured by the characteristic period $T_{g}$ (the predominant period of ground motion). Here, the $T_{g}$ is calculated by the formula $T_{g}=2 \pi \frac{v_{E}}{a_{E}}$ [24], where $\mathrm{a}_{\mathrm{E}}$ and $V_{E}$ are $1 / 4$ of the platform values corresponding to the absolute acceleration response spectrum and pseudovelocity response spectrum, respectively. The damping ratios of both spectra are 0.05 .

According the Seismic Ground Motion Parameter Zonation Map of China [25], the ground motion records of each soil type (I, II, III and IV) in Table 3 were further divided into three site groups according to the $\mathrm{T}_{\mathrm{g}}$. Table 3. Classified standard of ground motion based on $\mathrm{Tg}(\mathrm{sec})$.

\begin{tabular}{|c|c|c|c|c|}
\hline \multirow{2}{*}{$\begin{array}{c}\text { Site } \\
\text { group }\end{array}$} & \multicolumn{4}{|c|}{ Soil type } \\
\cline { 2 - 5 } & $I$ & $I I$ & $I I I$ & $I V$ \\
\hline Group 1 & $\leq 0.25$ & $\leq 0.40$ & $\leq 0.50$ & $\leq 0.70$ \\
\hline Group 2 & $0.25-0.35$ & $0.40-0.45$ & $0.50-0.65$ & $0.70-0.90$ \\
\hline Group 3 & $\geq 0.35$ & $\geq 0.45$ & $\geq 0.65$ & $\geq 0.90$ \\
\hline
\end{tabular}

\section{Effect Parameters of Simplified $\beta \mathrm{EH}$ HE Spectra}

The cumulative HE spectra are determined by the features of the estimated seismic oscillation at a given site and the dynamic behavior of the structure. This section explores the impacts of soil type, site group, structural damping ratio and ductility ratio on the $\mathrm{HE}$ demand of the SDOF system, which is represented by the dimensionless parameter $\beta_{E H}$.

\subsection{Soil type}

The mean $\beta_{E H}$ under the ground motions of site group 1 of soil types I, II, III and IV (Table 3) was computed at the ductility ratio of 2 , the damping ratio of 0.05 and the PSYR of 0.00 . It can be seen from Figure 1 that the soil type had a significant impact on the HE. The mean $\beta_{E H}$ spectra consist of the rising, stable and declining segments, which correspond to the short, medium and long periods, respectively. The $\beta_{E H}$ spectra of soil types I and II were relatively stable in the long term, but that of soil type IV plunged with the increase of the period. The $\beta_{E H}$ spectrum of soil type III fell between those of soil types I and II and soil type IV. From soil type I to IV, the peak $\beta_{E H}$ and peak period increased continuously.

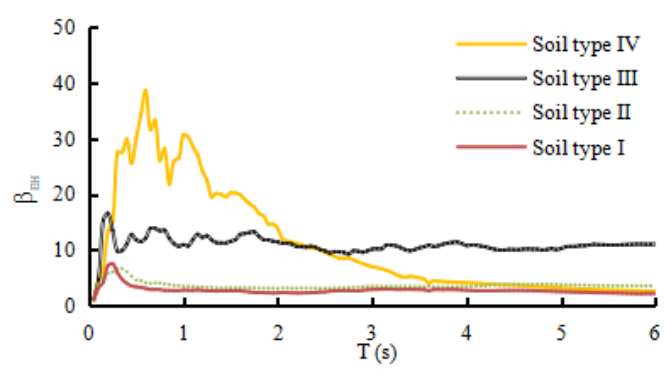

Figure 1. Effect of soil type: $\mu=2, p=0.0, \zeta=0.05$.

\subsection{Structural damping ratio}

The mean $\beta_{E H}$ spectra of the site groups 1,2 and 3 in the soil type II at different damping ratios are displayed in Figure $2(\mathrm{PGA}=0.2 \mathrm{~g}, \mu=2, \mathrm{p}=0.0$ and $\zeta=0.01,0.02$, $0.035,0.05,0.10$ and 0.20 ).

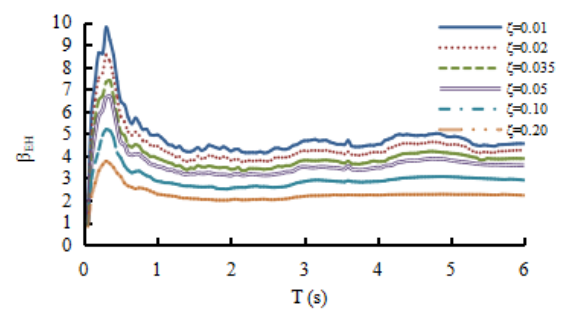

(a) Site group $1, \mu=2, p=0.0$

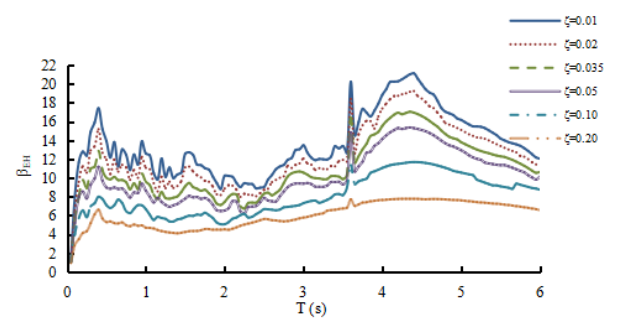

(b) Site group $2, \mu=2, p=0.0$

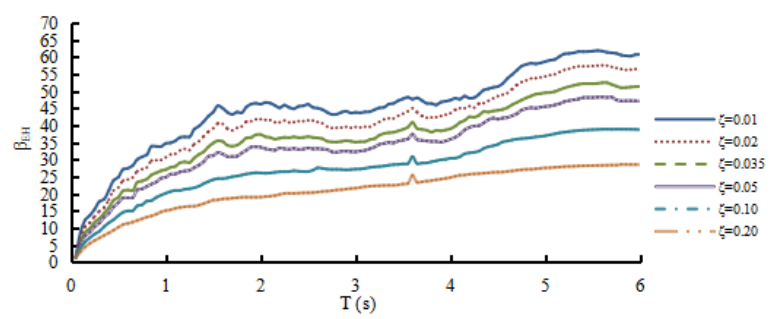

(c) Site group $3, \mu=2, p=0.0$

Figure 2. Effects of structural damping ratio.

As shown in Figure 2, the spectra underwent a negligible shift towards the right with the growing damping ratio. Meanwhile, the peak $\beta_{E H}$ of each site group dropped gradually, revealing the peak clipping effect of the damping ratio. The damping ratio had similar impacts on the $\beta_{E H}$ spectra, under the ground 
motions of different site groups at different soil types. Thus, the effects of damping ratio on peak $\beta_{E H}$ can be expressed by the same correction factor.

\subsection{Ductility ratio}

The mean $\beta_{E H}$ spectra of the site groups 1, 2 and 3 in the soil type II at different ductility ratios are shown in Figure $3(\mathrm{PGA}=0.2 \mathrm{~g}, \zeta=0.05, \mathrm{p}=0.0$ and $\mu=2,3,4,5,6,7$ and 8 ). Obviously, the $\beta_{E H}$ spectra values are sensitive to small variations in ductility ratio when the damping ratio remains constant. As the ductility ratio increased from 2 to 4 , the $\beta_{E H}$ value at constant period grew continuously, but became stable when the ductility ratio reached and surpassed 5. The phenomena demonstrate the limited effect of ductility ratio on spectral shape.

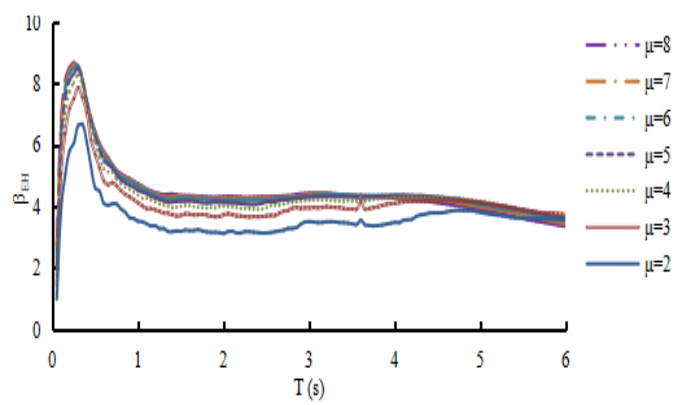

(a) Site group $1, \zeta=0.05, \mathrm{p}=0.0$

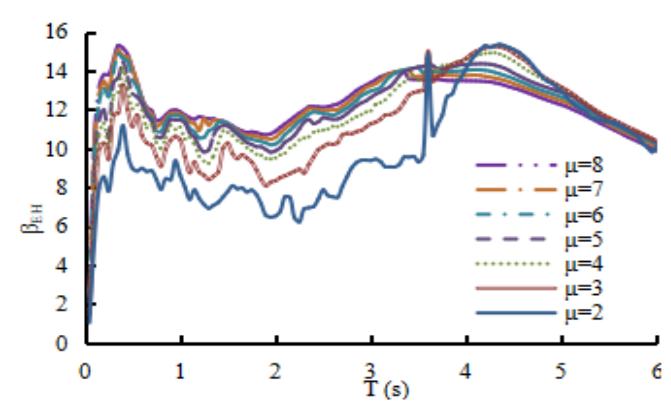

(b) Site group $2, \zeta=0.05, \mathrm{p}=0.0$

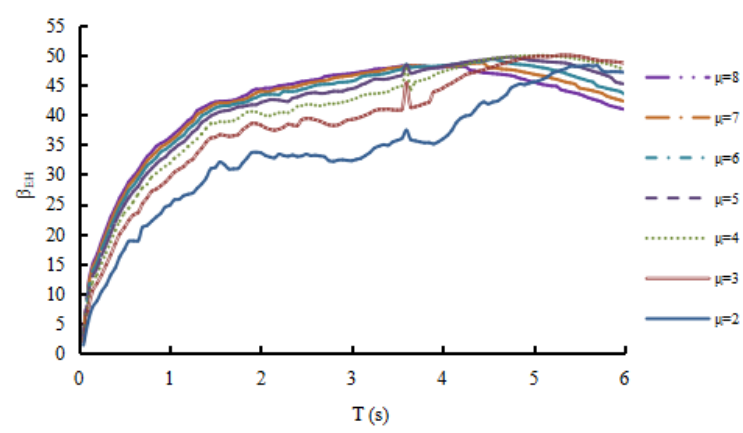

(c) Site group 3, $\zeta=0.05, \mathrm{p}=0.0$

Figure 3. Effect of structural ductility.

\subsection{Site group}

The mean $\beta_{E H}$ spectra of the site groups 1,2 and 3 in the soil type II are displayed in Figure 4 at $\mathrm{PGA}=0.2 \mathrm{~g}$, $\mu=2, p=0.05$ and $\zeta=0.05$. It can be seen that the site group has an important impact on the HE for the same soil type. The $\beta_{E H}$ spectra values increased linearly in the short period when the site group changed from 1 to 3 .

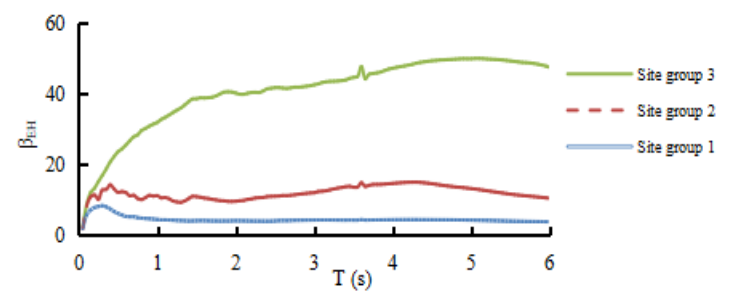

Figure 4. Effect of site group $(\mu=2, p=0.05, \zeta=0.05)$.

\section{Simplified $\beta_{E H}$ Spectra of Cumulative HE}

As mentioned above, the $\beta_{E H}$ spectra consist of the rising, stable and declining segments, and the spectral values are affected by the soil type, site group, damping ratio and ductility ratio. Hence, 12 groups of ground motions were classified by soil type and site group, and taken as the inputs. Then, the mean response of each group of ground motions was computed for the statistical analysis on the impacts from the damping ratio and ductility ratio. Figure 5 provides the fitted smooth spectral curves.

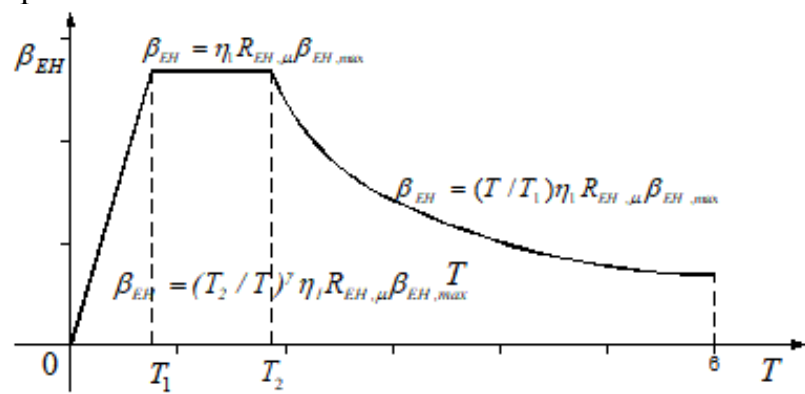

Figure 5. Three-segment model of equivalent velocity spectra of accumulated hysteretic energy.

The corresponding mathematical expressions are as follows:

$$
\begin{aligned}
& \beta_{E H}=\left(T / T_{1}\right) \eta_{1} R_{E H, \mu} \beta_{E H, \text { max }} \quad 0 \leq T<T_{1} \\
& \beta_{E H}=\eta_{1} R_{E H, \mu} \beta_{E H, \text { max }} \quad T_{1} \leq T \leq T_{2} \\
& \beta_{E H}=\left(T_{2} / T\right)^{\gamma} \eta_{1} R_{E H, \mu} \beta_{E H, \text { max }} \quad T_{2}<T \leq 6
\end{aligned}
$$

where $T_{l}$ is the separation period between the rising segment and horizontal segment, and $T_{2}$ is the separation period between the horizontal segment and declining segment; $T_{1}, T_{2}$ are relevant to soil type, site group and structural ductility, but are unrelated to structural damping; $\eta_{1}$ is the correction factor of structural damping ratio and is calculated by the equation (8); $R_{E H, \mu}$ is the 
structural ductility correction factor and is calculated by equation (9); $\gamma$ is the attenuation index of the declining segment and is calculated by the equation (10); $\beta_{E H, \max }$ is the peak $\beta_{E H}$ of cumulative $\mathrm{HE}$ at the acceleration amplitude of $0.2 \mathrm{~g}$, damping ratio of 0.05 , the PSYR of 0.0 and the ductility ratio of 2 .

(1) Correction factor of damping ratio $\left(\eta_{1}\right)$

The reference damping ratio of the elastic-plastic system was set to 0.05 . Considering the peak clipping effect of damping ratio on the $\beta_{E H}$ spectra of cumulative $\mathrm{HE}$, the correction factor can be defined as:

$$
\eta_{1}=\frac{\beta_{E H, \max , \zeta}}{\beta_{E H, \max , \zeta=0.05}}
$$

By analyzing the $\beta_{E H}$ spectra peak values under different structure damping ratios, it is found that the peak value decreases continuously with the increase of structural damping ratio. Such decrease is unrelated to soil types and site groups. Therefore, $\eta_{1}$ can be fitted by an inverse proportional function.The comparison between $\beta_{E H}$ peak values at different damping ratios shows that the peak value decreased continuously with the increase of the damping ratio. However, the decrease has nothing to do with soil type or site group. Hence, the $\eta_{1}$ can be fitted by an inverse proportional function:

$$
\eta_{1}=1+\frac{0.05-\zeta}{0.08+1.2 \zeta}
$$

where $\zeta$ is the damping ratio.

(2) Correction factor of ductility ratio $\left(R_{E H, \mu}\right)$

The values and shapes of $\beta_{E H}$ spectra are sensitive to $\mu$ when the latter is smaller than 5. Hence, the correction factor $\left(R_{E H, \mu}\right)$ can be defined as:

$$
R_{E H, \mu}=1+\frac{\mu-2}{2+2 \mu}
$$

where $\mu$ is the ductility ratio.

(3) Attenuation index $(\gamma)$ of the declining segment

As shown in Figure 2, the declining segment tended to be stable with the increase of damping ratio. The attenuation index $\gamma=\gamma_{1}+f(\zeta)$ was introduced to consider the shape variation of the $\beta_{E H}$ spectra. Note that the value of $f(\zeta)$ varies with site groups. For safety and simplicity, the $f(\zeta)$ was set to a small value under the constant $\zeta$. The $\gamma$ can be expressed as

$$
\gamma=\gamma_{1}+\frac{0.05-\zeta}{0.5+6 \zeta}
$$

where the values of $\gamma_{1}$ are listed in Table 4 , which are related to soil type and site group; $\zeta$ is the damping ratio.
Table $4 \beta_{E H}$ spectra parameters when acceleration amplitude is $0.2 \mathrm{~g}$.

\begin{tabular}{|c|c|c|c|c|c|}
\hline \multirow{4}{*}{$\begin{array}{c}\text { Soil } \\
\text { type }\end{array}$} & Site group & $\beta_{E H, \max }$ & $T_{1}(S)$ & $T_{2}(S)$ & $\gamma_{1}$ \\
\hline \multirow{4}{*}{$I$} & Group 1 & 6.5 & 0.15 & 0.35 & 0.35 \\
\cline { 2 - 6 } & Group 2 & 13 & 0.40 & 0.70 & 0.60 \\
\cline { 2 - 6 } & Group 3 & 26 & 1.30 & 2.85 & 0.45 \\
\hline \multirow{4}{*}{ II } & Group 1 & 6 & 0.10 & 0.45 & 0.22 \\
\cline { 2 - 6 } & Group 2 & 11 & 0.20 & 4.9 & 0.5 \\
\cline { 2 - 6 } & Group 3 & 35 & 1.4 & 5.8 & 0.02 \\
\hline \multirow{3}{*}{ Group 2 } & 18 & 0.40 & 2.5 & 0.75 \\
\cline { 2 - 6 } & Group 1 & 12 & 0.20 & 0.80 & 0.10 \\
\hline & Group 3 & 19 & 1.35 & 4.10 & 0.80 \\
\hline & Group 2 & 7.0 & 0.60 & 1.20 & 1.0 \\
\hline & Group 3 & 18.0 & 1.0 & 4.8 & 1.20 \\
\hline
\end{tabular}

(4) Periods $\left(T_{1}, T_{2}\right)$ of characteristic points

The periods $T_{1}$ and $T_{2}$, corresponding to the starting and end points of the horizontal segment, are related to soil type, site group and structural ductility, but their correlations with damping ratio can be neglected.There's a certain linear relationship between $T_{1}$ (or $\left.T_{2}\right)$ and $\mu$ : $T_{1}\left(o r T_{2}\right)=k \mu+b,(k<0, b>0)$.For the sake of simplification, the effects of $\mu$ can be neglected and the $T_{1}$ and $T_{2}$ values are listed in Table 4 .

(5) Peak $\beta_{E H}\left(\beta_{E H, \text { max }}\right)$

As shown in Table 4, $\beta_{E H \text {,max }}$ is the peak $\beta_{E H}$ in the stable segment at the acceleration amplitude of $0.2 \mathrm{~g}$. Here, the mean $\beta_{E H}$ values of each site group and soil type were selected, and fitted by the genetic algorithm on the Matlab. Figure 6 presents the fitted $\beta_{E H}$ spectra and the dynamic analysis results at different parameters.

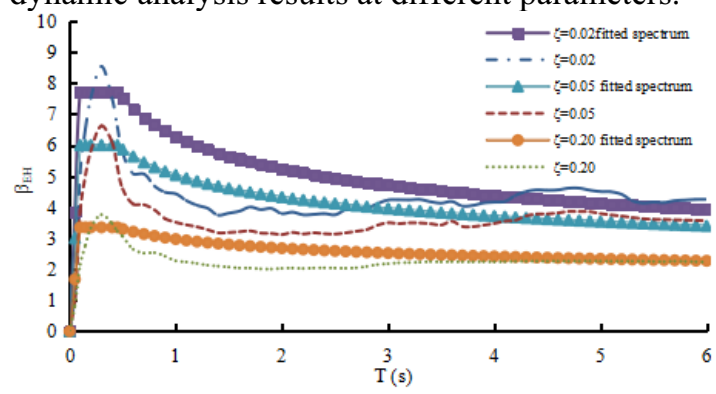

Figure 6. Comparison between fitted ${ }^{\beta}{ }_{E H}$ spectra and the dynamic analysis results of group 1 in soil type II under different damping ratios $(\mu=2$ and $\mathrm{p}=0)$. 


\section{Conclusions}

Considering the importance of structure energy demand in energy-based seismic design, this paper establishes normalized cumulative HE spectra according to Chinese soil site classifications, and draws the following conclusions through in-depth analysis:

(1) The soil type, site group and damping ratio have significant effects on the $\beta_{E H}$ spectra. As the soil type changed from I to IV, both the peak $\beta_{E H}$ and characteristic period increased continuously. The damping ratio has a peak clipping effect on the $\beta_{E H}$ spectra, and the effect remains the same in different site groups. For the same soil type, the peak $\beta_{E H}$ increased significantly as the site group changed from 1 to 3 .

(2) The shapes of $\beta_{E H}$ spectra have nothing to do with ductility ratio, while the spectra values are positively correlated with structural ductility when $\mu \leq 4$ and remains stable when $\mu \geq 5$.

(3) The $\beta_{E H}$ spectra consist of a rising segment, a stable segment and a declining segment. The separation periods $T_{1}$ and $T_{2}$ are related to soil type, site group and ductility ratio, but not to damping ratio.

Funding: This research was funded by the Natural Science Foundation of China (Grant no. 11604071); Natural Science Foundation of the Education Department of Anhui Province (Grant no. KJ2017A548); Natural Science Foundation of Hefei University(Grant Nos. 18ZR13ZDA, 18ZR14ZDA, 2017jyxm013,2019hfjyxm16) ; Major project of natural s cience research of Universities in Anhui province (KJ20 18ZD054) and the key project of university excellent young scholars for domestic and overseas visit,Anhui Province(gxfxZD2016217) .

Conflflicts of Interest: The authors declare that there is no conflflict of interest regarding the publication of this paper

\section{References}

1. G.W. Housner, Limit design of structures to resist earthquake, Proceedings of the 1st World Conference Earthquake Engineering. Berkeley, California, USA,(1956).

2. H. Akiyama, Earthquake-resistant Limit State Design for Buildings,University of Tokyo Press,Tokyo, Japan, 1985.

3. H. Akiyama, Earthquake resistant design based on the energy concept,Proceedings of the 9th World Conference on Earthquake Engineering,Tokyo,

Japan,(1988).

4. C.M.Uang, V.V.Bertero, Evaluation of seismic energy in structures, EARTHQUAKE ENGINEERING AND STRUCTURAL DYNAMICS.19(1),77-90,(1990) https://doi.org/10.1002/eqe.4290190108
5. R.K.Goel, Seismic response of asymmetric system: energy-based approach,JOURNAL OF STRUCTURAL ENGINEERING,ASCE. 123(11), 1444-1453,(1997). https://doi.org/10.1061/(ASCE)07339445(1997)123:11(1444)

6. S. Leelataviwat, S.C.Goel, B. Stojadinović, Energy based seismic design of structures using yield mechanism and target drift, Journal of Structural Engineering, ASCE. 127(8), 1046-1054,(2002). https://doi.org/10.1061/(ASCE)0733-9445(2002)

$128: 8(1046)$

7. H. Choi, J. Kim, Energy-based seismic design of buckling-restrained braced frames using hysteretic energy spectrum, Engineering Structures.28(2), 304-311, (2006)

https://doi.org/10.1016/j.engstruct.2005.08.008

8. D.R.Sahoo, S.H.Chao, Performance-based plastic design method for buckling-restrained braced frames, Engineering Structures.32(9),2950-2958,(2010).

https://doi.org/10.1016/j.engstruct.2010.05.014

9. S.B. Kharmale,S. Ghosh, Performance-based plastic design of steel plate shear wall, Journal of Constructional Steel Research.90(5), 85-97,(2013). https://doi.org/10.1016/j.jcsr.2013.07.029

10. A. Habibi , R.W.K. Chan, F.Albermani, Energybased design method for seismic retrofitting with passive energy dissipation systems, Engineering Structures.46(1), 77-86,(2013). https://doi.org/10.1016/j.engstruct.2012.07.011

11. A.Heidari, S. Gharehbaghi, Seismic performance improvement of special truss moment frames using damage and energy concepts, EARTHQUAKE ENGINEERING \& STRUCTURAL DYNAMICS.44(7), 1055-1073,(2015). https://doi.org/10.1002/eqe.2499

12. W.E. McKevitt,D.L.Anderson, S.Cherry, Hysteretic energy spectra in seismic design, In:Proceedings of the 2nd World Conference on Earthquake Engineering.7,487-494,(1980)

13. P.Khashaee Energy-based seismic design and damage assessment for structures, $\mathrm{PhD}$ Thesis.School of Engineering, Southern Methodist University, Dallas, Texas,(2004).

14. F. López-Almansa, U.Yazgan, A. Benavent-Climent, Design energy input spectra for high seismicity regions based on Turkish registers, Bulletin of Earthquake Engineering . 11(4), 885-912,(2013). https://doi.org/10.1007/s10518-012-9415-2

15. F.Wang, H.N. Li, T.H.Yi, Energy spectra of constant ductility factors for orthogonal bidirectional earthquake excitations, Advances in Structural Engineering. 18(11), 1877-1899,(2015)

.https://doi.org/10.1260\%2F1369-4332.18.11.1887

16. F. Wang, H.N. Li, N.Zhang, A method for evaluating earthquake-induced structural damage based on displacement and hysteretic energy, Advances in Structural Engineering.19(7), 1165-1176,(2016). https://doi.org/10.1177\%2F1369433216634505

17. G.H. Sun, Q. Gu, Y.Z.Fang, A simplified normalized cumulative hysteretic energy spectrum, Earthquakes and Structures. 12(2), 177- 
189,(2017).https://doi.org/10.12989/eas.2017.12.1.17 7

18. S.Dogru, B. Aksar, B.Akbas, J.Shen, Parametric study on energy demands for steel special concentrically braced frames, Steel and Composite Structures.24(2),pp.265-276,(2017). https://doi.org/10.12989/scs.2017.24.2.265

19. M.Bruneau ,N.Wang , Some aspects of energy methods for the inelastic seismic response of ductile SDOF structures, Engineering Structures.18(1), 112,(1996). https://doi.org/10.1016/01410296(95)00099-X

20. C.C.Chou, C.M.Uang , An evaluation of seismic energy demand: An attenuation approach, PEER Report 2000/04 Pacific Earthquake Engineering Research Center, College of Engineering, University of California, Berkeley, (2000).

21. S.W. Geng, Strong Ground Motion Input Parameter For Seismic Design, Doctor's Thesis.Institute of Engineering Mechanics, China Earthquake Administration,Harbin,Heilongjiang,(2005).(In Chinese).

22. GB50011-2010. Code for seismic design of buildings, Ministry of Housing and Urban-Rural Development of the People's Republic China, Beijing, China,(2010).(In Chinese).

23. H.S.Lv, An earthquake Risk Analysis Method Based On Seismic Ground Motion Parameters, Doctor's Thesis.Institute of Geophysics, China Earthquake Administration, Beijing, China,(2005).(In Chinese).

24. Y.X.Yu, S.Y.Li, L.Xiao, Attenuation relation of ground motion established for drawing up new seismic ground motion parameter zonation map, Technology for Earthquake Disaster Prevention. ,8(1), 24-33,(2013). (In Chinese)

25. GB18306-2015. Seismic Ground Motion Parameter Zonation Map of China, Standardization Administration of the People's Republic of China,Beijing,China,(2015).(In Chinese). 